\title{
Pharmacological Molecule Based on Nanocarbon Container Encapsulated Ferromagnet by Combustion Synthesis for Cancer Therapy
}

\author{
Badis Bendjemil ${ }^{1,2, ~}$, Abdelaziz Lankar ${ }^{3}$, Djelloul Messadi ${ }^{1}$, Dominique Vrel ${ }^{4}$ \\ ${ }^{1}$ LASEA, Dept. of Chemistry, University of Badji-Mokhtar, 23000 Annaba, Algeria \\ ${ }^{2}$ Dept. of Mechanical Engineering, University of 8 Mai 1945 Guelma, 24000 Guelma, Algeria \\ ${ }^{3}$ Laboratoire Central d'Anatomie et de Cytologie Pathologiques CHU, 23000 Annaba, Algeria \\ ${ }^{4}$ LSPM, Université Paris 13, Sorbonne Paris Cité, 99 Av. J. B. Clément, 93430 Villetaneuse, France \\ *Corresponding Author: Badis23@ymail.com
}

Copyright (C) 2014 Horizon Research Publishing All rights reserved.

\begin{abstract}
Combustion synthesis in electrothermal explosion mode can be regarded as an efficient method to obtain new nanomaterials. Different starting mixtures of magnesium powder with various carbonates $\left(\mathrm{Li}_{2} \mathrm{CO}_{3}\right.$, $\left.\mathrm{Na}_{2} \mathrm{CO}_{3}, \mathrm{CaCO}_{3}, \mathrm{FeCO}_{3},\left(\mathrm{NH}_{4}\right)_{2} \mathrm{CO}_{3}\right)$ were tried and the self-thermal reactions were carried out under both reactive (air) and neutral atmosphere (argon) with an initial pressure of $10 \mathrm{~atm}$ to yield novel nanomaterials. $\mathrm{Fe}, \mathrm{Co}, \mathrm{Ni}, \mathrm{Pd}, \mathrm{Nd}$, $\mathrm{Ta}, \mathrm{Ti}, \mathrm{Nb}, \mathrm{W}$ and $\mathrm{NiO}$ powders were used as catalysts and their synthesis and purification have been optimized. Under the applied conditions the presence of crystalline $\mathrm{MgO}$ and $\mathrm{NaO}_{2}$ in products confirmed by XRD analysis, even for the reaction under neutral atmosphere, points to the deep conversion of carbonates. For producing fibrous products the $\mathrm{Na}_{2} \mathrm{CO}_{3}$ system proved to be the most promising one. FESEM images show the morphology of the products with some 1-D nanostructures resembling carbon nanotubes and nanosized metal/carbon composite (carbon-encapsulated metal-based iron nanoparticles with a core-shell structure with interesting magnetic properties by combustion was obtained. Different magnetic metals ( $\mathrm{Fe}, \mathrm{Ni}$, and $\mathrm{Co}$ ) that can be encapsulated by the carbon shell, graphite layers and nanofibers. After purification procedure, we will only obtain core-shell or graphite layers encapsulated by metal magnetic nanoparticles without impurity like noncoated iron or carbides and amorphous carbon. The characterization techniques include the chemical analysis, HRTEM, XRD and FESEM.. The obtained novel pharmacological molecular nanostructure will be injected in the cancer tumor cell (prostate) after sterilization. The nanocontainer will be heated by microwave at the Laboratory Central of Anatomie and Cytology Pathology of the CHU Annaba. The reaction will be observed in the HRTEM.
\end{abstract}

Keywords 1-D Nanostructures, Core-Shell Structure, Graphite Layers, Nano Container Carbon Ferromagnet, Nanofibers
PACS: 47.61.-k, 88.30.rh, 68.37.Lp.

\section{Introduction}

For very long time carbon was known as the fundamental component of different chemical species. These compounds create foundation of living organisms, including plants and animals. It is therefore understandable that these compounds were subject of intensive research, creating an immense branch of science known as organic chemistry. The investigations in these areas were very intense, resulting in many discoveries which affected not only scientific understanding of fundamentals of chemistry, physics and biology but also transformed many areas of industrial activity, and deeply changed our everyday life. It is therefore surprising, that the subject was not exhausted; on the contrary, recent discoveries channeled interest of many researchers in this direction. Among significant achievements in the area, the most prominent was the discovery of nanosize carbon structures, such as fullerenes [1, 2], carbon nanotubes (CNTs) [3] or graphene [4-6] and related materials [44]. These discoveries heralded advent of new branch of science and nanotechnology.

The molecular nanostructures of carbon (CNTs) have interesting optical and electrical properties, which can be modified by introduction of foreign atoms [7]. It is also important that this development was connected with the progress in the most important characterization tool. High Resolution Transmission Electron Microscopy (HRTEM) that allowed studying these structures with atomic precision. Another discovery of self-standing graphene attracted more attention to this area [4-6]. This discovery was even more surprising, as graphene is intimately related to graphite, the material known for centuries. The electric properties of graphene made this material a focal point of the 
semiconductor research promising new very attractive applications in high-speed electronics [8, 9].

Application of graphene-based devices requires deposition of graphene on a mechanically strong support. The optimal choice would be fabrication of graphene on a carbon-based material such as silicon carbide. It was therefore fortunate that graphitic films can be grown on $\mathrm{SiC}$ surfaces [10-12]. It was recognized only recently that few atomic carbon layers have the electronic transport properties of graphene [13]. It is evident that most important is the structure of the $\mathrm{SiC}$-graphene interface. Therefore the atomistic structure was intensively investigated [14, 15]. Despite some progress, the relations between the atomistic structures of carbon layers deposited on $\mathrm{SiC}$ surfaces are not well understood. Another aspect of the interaction of graphite-like carbons layers with solid supports is related to carbon-metal structures. In contrast to graphene-SiC structures, which are relatively easy to obtain, the carbon-metal structures are more difficult to synthesize. This is related to the fact that carbon is easily dissolved in liquid metals, creating solid solutions or in higher concentrations, metal carbides [16]. Therefore in order to synthesize such structures, rapid high-temperature methods have to be used. Fast, high-temperature stage of the synthesis of carbon layers on metal surfaces should be followed by rapid cooling down of the system in order to prevent dissolution of carbon layer in the metal interior. Among the processes that are able to fulfill such criteria, the most effective are: Huffman-Krätschmer arc process [17] and combustion synthesis [18, 19]. Therefore combustion synthesis is a technologically important process. In particular, application of the combustion process to creation of $\mathrm{Me}-\mathrm{C}$ structures. It has to be noted that carbon encapsulation of metal nanoparticles changes their properties. These particles create a new-type material combining magnetic and other physical properties of metals with chemical resistance of carbon. They create a new type of structural nanosize materials, which demonstrate the potential of nanotechnology. As such their properties are extremely interesting from the point of materials science and also for their potential applications. Therefore their properties are intensively investigated [20]. The results of the characterization of such systems by many methods will also be reviewed. Their properties open routes to many applications in industry and medicine and other branches of human activity [21]. Therefore such possibilities of potential applications will also be discussed.

\section{Experimental Procedure}

Combustion was carried out in an electrothermal explosion (ETE) reactor (Fig. 1). The effect of process parameters such as reactant composition (powdered $\mathrm{Mg} /$ carbonate), initial combustion pressure (1-10 atm), and atmosphere (air, argon, CO, and nitrogen) was studied. The products (Fig. 2) were characterized by XRD, scanning electron microscopy (FESEM), high-resolution transmission electron microscopy (HRTEM), and Raman spectroscopy. Purification procedure of the products was proposed and will be performed. The powder mixture of reactants was placed in a cooper tube decrees the projection of the materials by shock-wave induced by the reaction; they was initiated by heavy-current heating and terminated usually within less than $2 \mathrm{~min}$.

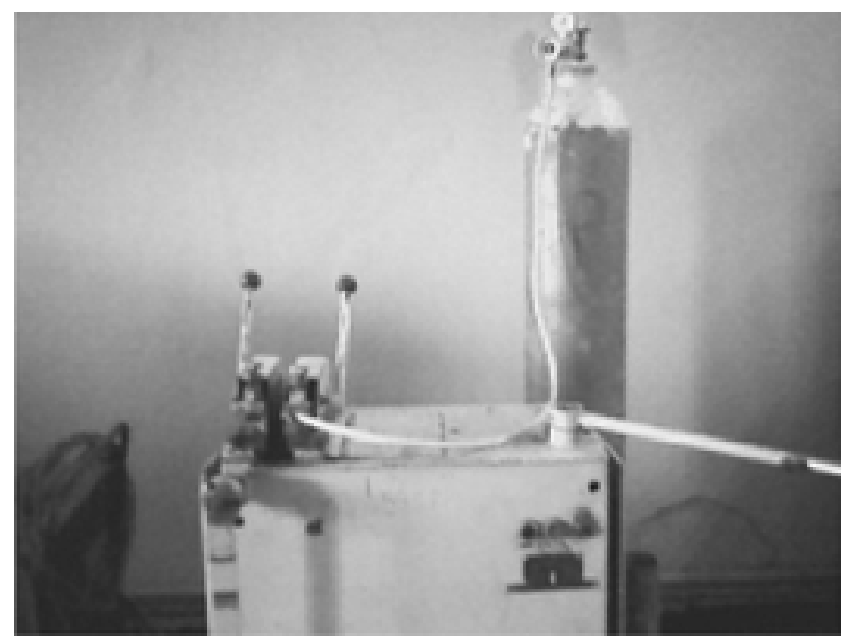

Figure 1. Overall view of the electrothermal explosion reactor reaction; they was initiated by heavy-current heating and terminated usually within less than $2 \mathrm{~min}$
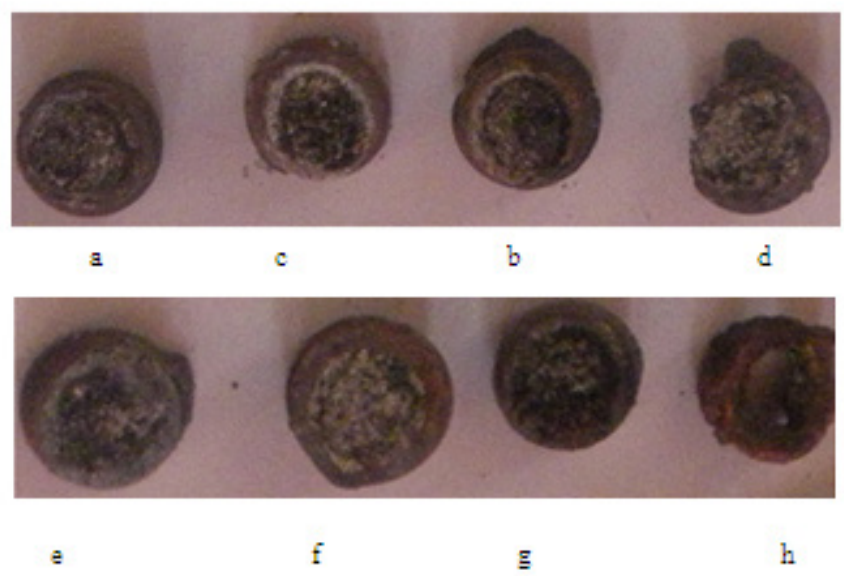

Figure 2. Samples pictures of the combustion products obtained from carbonate systems with and without metals catalysts incorporated in cooper tubes: (a) $\mathrm{Na}_{2} \mathrm{CO}_{3} / \mathrm{Mg}, 1 \mathrm{~atm}$ argon,(b) $\mathrm{Na}_{2} \mathrm{CO}_{3} / \mathrm{Mg} / \mathrm{Fe}$, 1 atm argon, (c) $\mathrm{Na}_{2} \mathrm{CO}_{3} / \mathrm{Mg} / \mathrm{Ni}, 1$ atm argon, (d) $\mathrm{Na}_{2} \mathrm{CO}_{3} / \mathrm{Mg} / \mathrm{Co}, 1$ atm argon, (e) $\mathrm{Na}_{2} \mathrm{CO}_{3} / \mathrm{Mg} / \mathrm{Ta}, 1$ atm , (f) $\mathrm{Na}_{2} \mathrm{CO}_{3} / \mathrm{Mg} / \mathrm{Ti}, 1$ atm , (g) $\mathrm{Na}_{2} \mathrm{CO}_{3} / \mathrm{Mg} / \mathrm{Pd}, 1$ atm, (h) $\mathrm{Na}_{2} \mathrm{CO}_{3} / \mathrm{Mg} / \mathrm{Nd}, 1 \mathrm{~atm}$.

\subsection{ETE Process in Carbonate Systems}

Different starting homogenous mixtures of $\mathrm{Mg}$ powder (Sigma-Aldrich, $>99 \%$ ) with various carbonates $\mathrm{Na}_{2} \mathrm{CO}_{3}$ from Sigma Aldrich, $>99 \%$ and $\mathrm{CaCO}_{3}$ from Sigma-Aldrich, $>99 \%$ as a source of elemental carbon, were 
tried; reactions were carried out under reactive (air) or neutral atmosphere (argon) at an initial pressure of $10 \mathrm{~atm}$. The blends were prepared in a high energy Fritsch planetary ball mill. The rotation speed could be varied within the range 400-600 rpm. In order to avoid oxidation during alloying, the ball mill was filled with high purity argon gas. The vial was opened after 30-45 min to assure high homogenization, fractioning, and cold welding of the particles. The powders were compacted into small discs $[(2-3) \times 13 \mathrm{~mm}]$ at the compacting pressure $P=6000 \mathrm{psi}$ and put into a cooper tube; $\mathrm{Fe}, \mathrm{Co}, \mathrm{Ni}, \mathrm{Pd}, \mathrm{Nd}$ and $\mathrm{NiO}$ powders (325 mesh) were used as catalysts.

Assumed reactions, composition of the mixtures, their standard thermodynamic parameters, and measured heats of reactions are given in Table 1. High adiabatic temperatures, especially these in excess of $2000 \mathrm{~K}$ (Table 1), make the combustion method as perspective as carbon arc plasma methods, also capable to provide extremely high temperatures, above $3000 \mathrm{~K}[17,20]$. For comparison, the last column in Table 1 presents the measured values of reaction heats (at constant volume). They are seen to correlate with calculated standard enthalpy of reactions.

The noncoated iron or carbides and encapsulated iron is not detected because is segreget with small concentration. The EDX analysis (Fig.6), demonstrates that the reaction under neutral atmosphere leads to a deep conversion of carbonates. For producing fibrous products (Fig. 4), the $\mathrm{Na}_{2} \mathrm{CO}_{3}$ system proved to be the most promising one; in other tested carbonate systems, except $\mathrm{Li}_{2} \mathrm{CO}_{3}$, the content of fibrous phase was negligibly small. The FESEM pictures (Fig. 4) show the morphology of the products with some 1D nanostructures resembling carbon nanotubes (CNTs) and nanofibers (Fig. 4) without and with $\mathrm{Fe}, \mathrm{Ni}, \mathrm{Pd}$ and $\mathrm{Co}$ catalysts (Figs. 4a-m), in comparison with the nanostructures reported in [40] (Figs. 4f, g, h).

Table 1. Assumed reqctions compositions and thermodynamic parameters

\begin{tabular}{|c|c|c|c|c|c|c|c|}
\hline Assumed r eactions & $\begin{array}{c}\text { Composition, } \\
\text { wt. } \%\end{array}$ & $\begin{array}{c}\text { Catalys } \\
\mathrm{t} \\
\end{array}$ & $\begin{array}{c}\Delta S^{o} \\
\mathrm{~J} / \mathrm{kg} \cdot \mathrm{K}\end{array}$ & $\begin{array}{c}\Delta H^{o} \\
\mathrm{~kJ} / \mathrm{kg}\end{array}$ & $\begin{array}{c}\Delta G^{o} \\
\mathbf{k J} / \mathrm{kg}\end{array}$ & $\begin{array}{c}T_{a b} \\
\mathbf{K}\end{array}$ & $\begin{array}{c}Q,{ }^{\prime}, \\
\mathrm{kJ} / \mathrm{kg}\end{array}$ \\
\hline $\begin{aligned} & \mathrm{Na}_{2} \mathrm{CO}_{3}+3 \mathrm{Mg} \\
= & 3 \mathrm{MgO}+\mathrm{C}+2 \mathrm{Na}\end{aligned}$ & $\begin{array}{c}\mathrm{Na}_{2} \mathrm{CO}_{3} / \mathrm{Mg} \\
(70 / 30)\end{array}$ & $\begin{array}{c}\mathrm{Fe},(\mathbf{1 0}) \\
\mathrm{N}, \\
\mathrm{Co}, \\
\mathrm{NiO}\end{array}$ & 2392 & -3750 & -4463 & 2300 & 2388 \\
\hline $\begin{array}{c}\mathrm{CaCO}_{3}+2 \mathrm{Mg}= \\
2 \mathrm{MgO}+\mathrm{CaO}+\mathrm{C}\end{array}$ & $\begin{array}{c}\mathrm{CaCO}_{3} / \mathrm{Mg} \\
(70 / 30)\end{array}$ & $\begin{array}{c}\mathrm{Fe},(10) \\
\mathrm{N}, \\
\mathrm{Co}, \\
\mathrm{Pd}, \\
\mathrm{Nd}, \\
\mathrm{NiO}\end{array}$ & 2007 & -3513 & -4111 & 2175 & 3100 \\
\hline
\end{tabular}

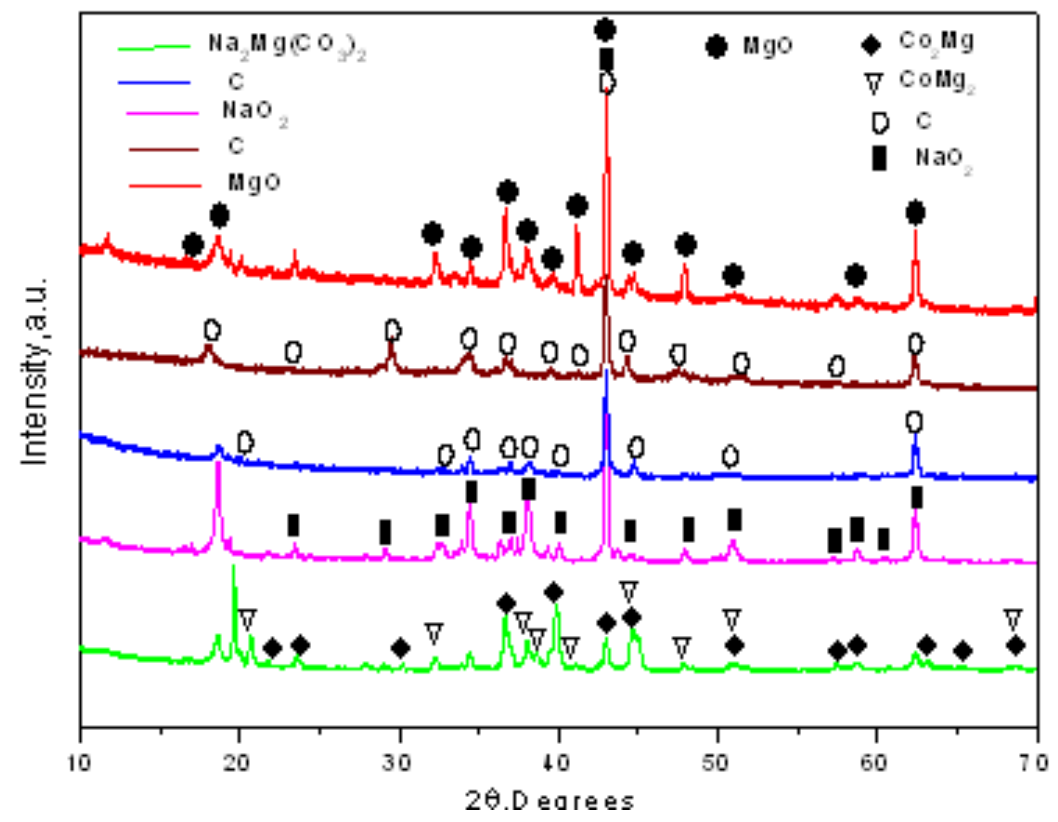

Figure 3. XRD pattern of the combustion products obtained from carbonate systems with and without metals catalysts: (green line) $\mathrm{Na}_{2} \mathrm{CO}_{3} / \mathrm{Mg}, 1 \mathrm{~atm}$ argon, (bleu line) $\mathrm{Na}_{2} \mathrm{CO}_{3} / \mathrm{Mg} / \mathrm{Fe}, 1$ atm argon, (pink line) $\mathrm{Na}_{2} \mathrm{CO}_{3} / \mathrm{Mg} / \mathrm{Ni}, 1$ atm argon, (dark red line) $\mathrm{Na}_{2} \mathrm{CO}_{3} / \mathrm{Mg} / \mathrm{Co}, 1$ atm argon, (rot line) CaCO $3 / \mathrm{Mg}, 1$ atm argon. 


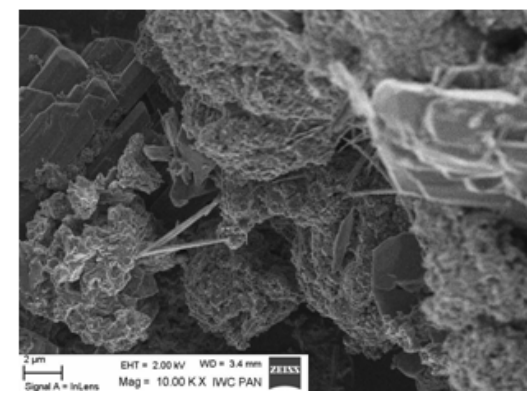

(a)

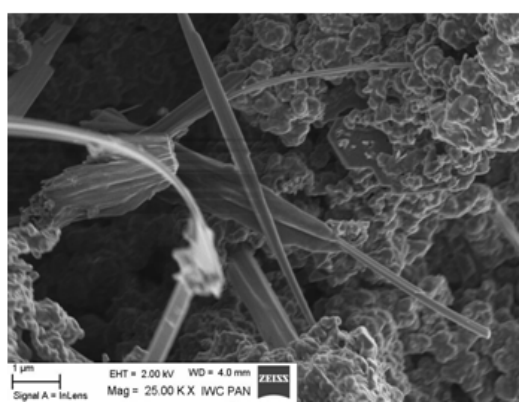

(c)

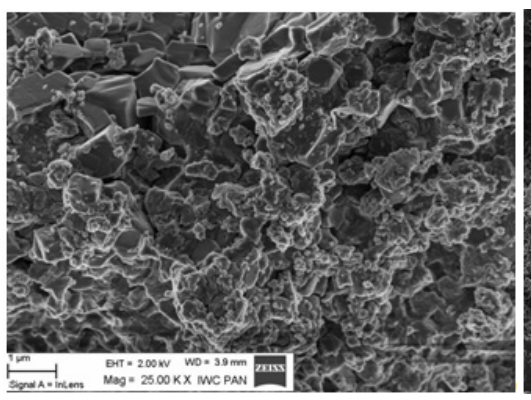

(e)

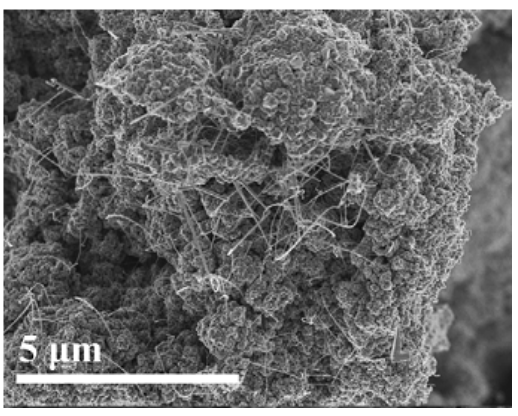

(g) $[40]$

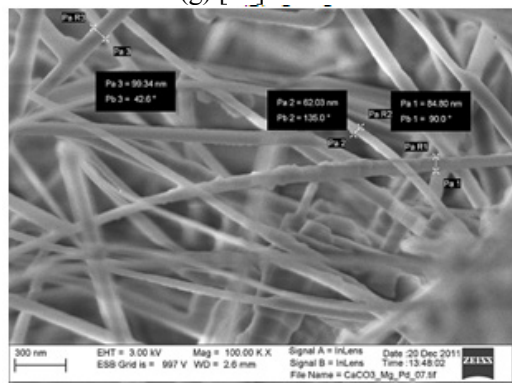

$(\mathrm{m})$

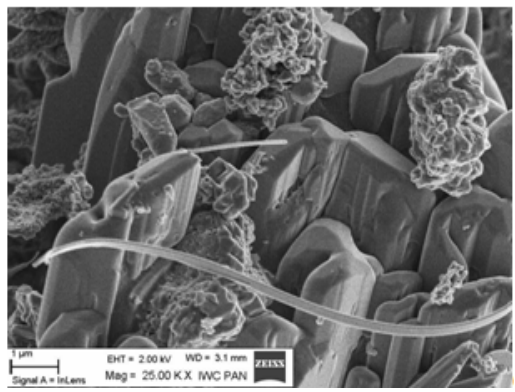

(b)

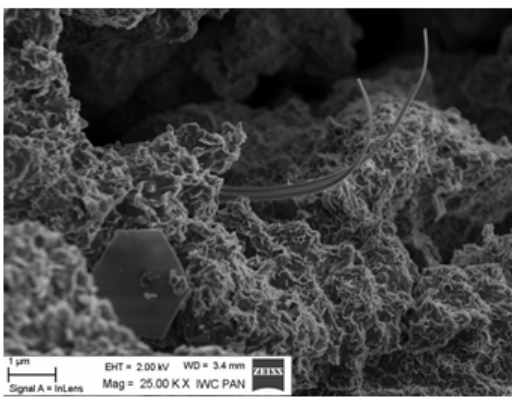

(d)

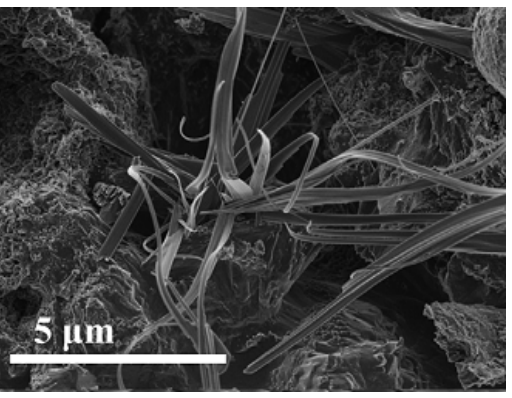

(f) $[40]$

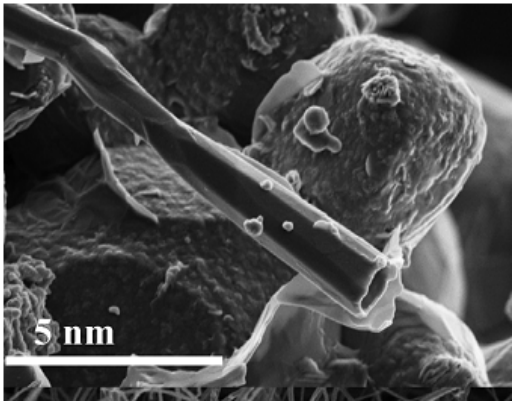

(h) [40]

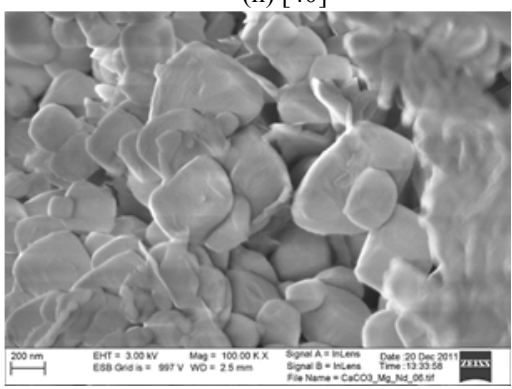

(n)

Figure 4. FESEM pictures of the combustion products obtained from carbonate systems with and without metals catalysts: (a) $\mathrm{Na}_{2} \mathrm{CO}_{3} / \mathrm{Mg}, 1 \mathrm{~atm}$ argon, (b) $\mathrm{Na}_{2} \mathrm{CO}_{3} / \mathrm{Mg} / \mathrm{Fe}$, 1 atm argon,(c) $\mathrm{Na}_{2} \mathrm{CO}_{3} / \mathrm{Mg} / \mathrm{Ni}, 1$ atm argon, (d) $\mathrm{Na}_{2} \mathrm{CO}_{3} / \mathrm{Mg} / \mathrm{Co}, 1$ atm argon, (e) $\mathrm{CaCO}_{3} / \mathrm{Mg}, 1$ atm argon, (f) $\mathrm{Na} 2 \mathrm{CO} / \mathrm{Mg} / \mathrm{Co}, 101$ atm (f), air, (g) $\mathrm{Na}_{2} \mathrm{CO}_{3} / \mathrm{Mg} / \mathrm{PTFE} / \mathrm{Fe}, 10 \mathrm{~atm}$, air [40], (h) $\mathrm{FeCO}_{3} / \mathrm{Mg}, 10 \mathrm{~atm}$, air [40], (m) $\mathrm{CaCO}_{3} / \mathrm{Mg} / \mathrm{Pd}, 1 \mathrm{~atm}$ argon, (n) $\mathrm{CaCO}_{3} / \mathrm{Mg} / \mathrm{Nd}, 1 \mathrm{~atm}$ argon 


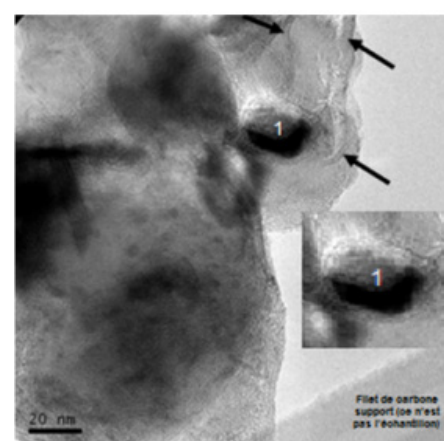

(a)

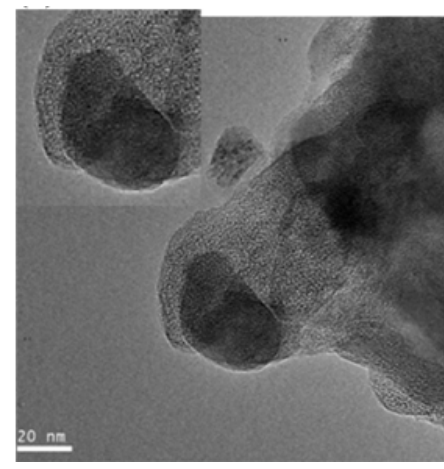

(c)

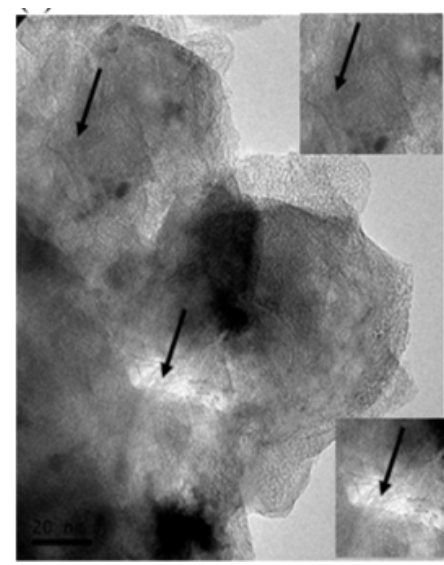

(e)

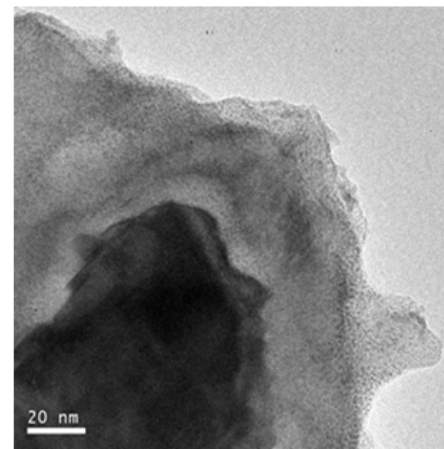

(g)

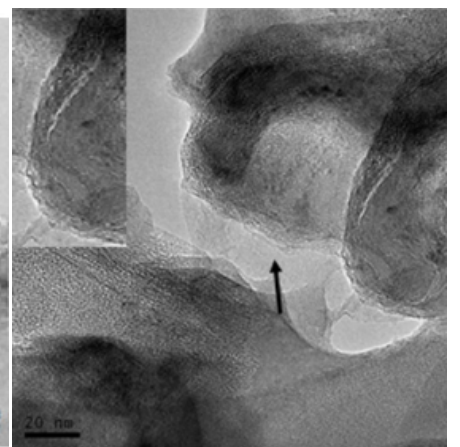

(b)

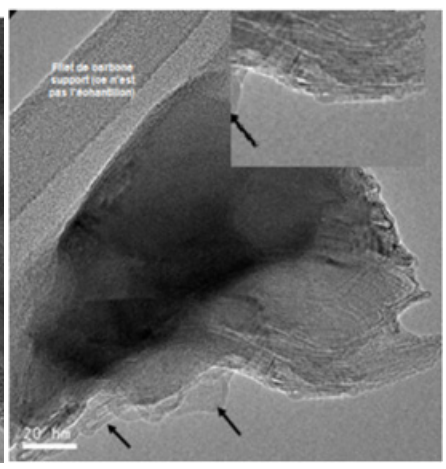

(d)

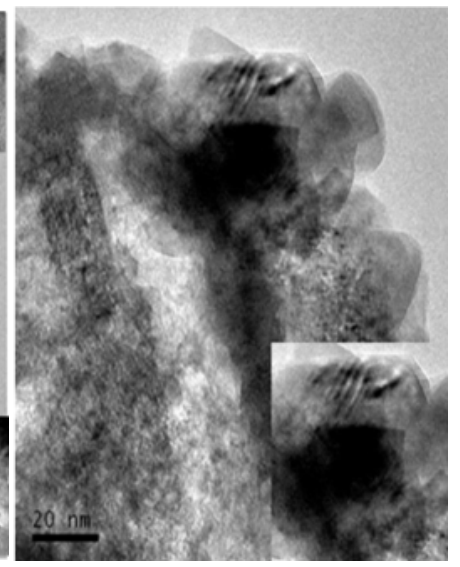

(f)

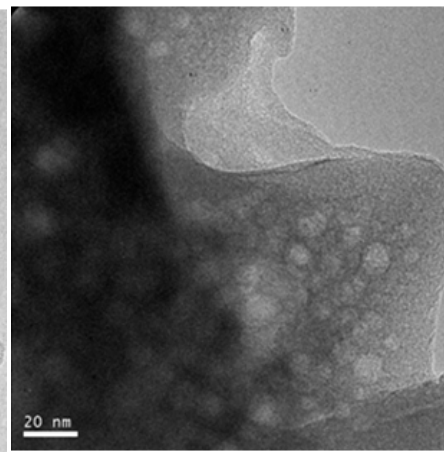

(h)

Figure 5. a, b, c, $\mathbf{d}$ corresponding to the HRTEM pictures of the nanostructures obtained in combustion synthesis of $\mathrm{Na}_{2} \mathrm{CO}_{3} / \mathrm{Mg} / \mathrm{Fe}$ systems, 1 atm argon, showing encapsulation of $\mathrm{Fe}$ or $\mathrm{Fe}_{3} \mathrm{C}$ nanoparticles of about $20 \mathrm{~nm}$ thick by graphitic layers: inset in the right corner shows the magnified part of the nanoparticle $\mathrm{Fe}$ and $\mathrm{Fe}_{3} \mathrm{C}$; (c) amorphous carbon; (b) and (d) nanoparticles by additional thick graphite layers growing on the thin $\mathrm{C}$ - particles, -e, $\mathbf{f}, \mathbf{g}, \mathbf{h}$ corresponding to $\mathrm{Na}_{2} \mathrm{CO}_{3} / \mathrm{Mg}$, systems $1 \mathrm{~atm}$ argon, that represented organic and mineral materials resulting from the reactions, nanotubes and graphite layers. 
In fact, Huczko et al. [26] and Alekseev et al. [36] have shown that condensing carbon vapors by combustion of carbonates (produced via SHS) can yield CNTs. Also, Bendjemil et al. [37, 38] reported on production of carbon nanotubes upon gas combustion (decomposition of $\mathrm{Fe}(\mathrm{CO})_{5}$ at low pressures and moderate temperatures, one should mention that $\mathrm{CO}_{2}$ ), which is in fact, an intermediate reactant of our carbonate decomposition under combustion synthesis conditions, can be reduced to CNTs by metallic Li [39]. The images of the typical carbon-shell, graphite layers, Fe or $\mathrm{Fe}_{3} \mathrm{C}$ containing encapsulates are presented in Figs. $5 \mathrm{a}-\mathrm{d}$. In these images the following particles are observed: $\mathrm{Fe}$ or $\mathrm{Fe}_{3} \mathrm{C}$ nanoparticles, surrounded by graphitic envelope, adhered to the metal nanoparticles; the nanoparticles surrounded by thin graphite envelopes on which secondary, much thicker graphite layer is created (Figs. 5a-c) and nanotubes. Such thick graphite structures are created due to nonuniform enveloping of the grains surfaces, resulting in encapsulation of the grain in the zones of considerably different temperatures. The series of images demonstrates transition from amorphous carbons structure, presented in (Fig. 5d), the presented nanoparticles are shown in the insets located in the corners. Fig $5 \mathrm{e}, \mathrm{f}, \mathrm{g}$, h corresponding to $\mathrm{Na}_{2} \mathrm{CO}_{3} / \mathrm{Mg}$, systems $1 \mathrm{~atm}$ argon, that represented organic and mineral materials resulting from the reactions and nanotubes.

It has to be noted that the combustion synthesis suffers from some drawbacks at the moment. This are related to relatively small portion of useful Me-containing products. This is partially caused by relatively low temperature of the process. Still the adiabatic temperatures, listed in table 1 are high, exceeding $2000 \mathrm{~K}$ for some cases, close to those attained by arc-discharge technique. Thus, low efficiency is partially related to the fact that the area is in the early stage of development. Therefore intensive research of the process is necessary to develop combustion detonation and shock synthesis (CDS), before the method could be industrially attractive. This research will be directed towards achievement of higher content of Me-containing particles, control of particle size distribution, and also the structure of the particles.

\subsection{Kinetic Model Formation of Pharmacological Molecule Based on Core-Shell (Nanocontainer Carbon Ferromagnet}

Their core is nonokristallit ferromagnet. It is chemically fonctionnalized by nanoparticle for biologically active nanocapsule is hypothetically, be placed in a manner controlled, with the magnetic field head for human organism (drug delivery, cancer therapy).

The Figure shows the model of kenitic formation use for the pharmacological molecule. Such new nanomaterial preceded must be research their possible actions and reactions with the graphitic core or matrix.

\section{Conclusions}

Under the applied conditions the presence of crystalline $\mathrm{MgO}$ and carbon as source of $1 \mathrm{D}$ nanostructures the in the products confirmed by XRD analysis, the reaction under neutral atmosphere, points to the deep conversion of carbonates. For producing fibrous products the $\mathrm{Na}_{2} \mathrm{CO}_{3}$ system proved to be the most promising one (in other of tested carbonate systems, except $\mathrm{Li}_{2} \mathrm{CO}_{3}$, the content of fibrous phase was insignificantly small). FESEM pictures show the morphology of the products with some 1-D nanostructures resembling to carbon nanotubes and nonofibers. Carbon encapsulated magnetic nanoparticles belong to the newest, rapidly developed branch of nanotechnology science. These structures were developed recently as a part of wide are of investigations of carbon based nanostructures: fullerenes, nanotubes, graphene, etc. Starting from purely carbon domain these structures penetrated into more sophisticated design: combination of metals and carbon.

\section{Perspective}

This combination offers new perspectives, not available to standard carbon-based structures. magnetic properties of iron, cobalt, nickel etc. can be preserved in nanoscale small volumes. Carbon encapsulation makes the nanoparticles stable, resistant, harmless. They could preserve their unique properties for very long time in extremely aggressive chemical environment, at high temperatures or both. In conjunction with the small size and possibility of control by magnetic field, this offers wide area of applications, such as magnetic data storage, xerography, electronics, magnetic resonance imaging, and catalysis [21]. Other important applications remain in nanomedicine, e.g. transport of anticancer drugs, or fine surgical interventions. Many different synthesis techniques were used to obtain such nanocarbon encapsulated nanoparticles: carbon plasma arc-discharge [17, 20], RF plasma torch [31], magnetron and ion beam co-sputtering [32], high temperature annealing of the mixtures of carbon-based materials and metal containing powders [33], pyrolysis of organometallic compounds [18] and catalytic carbonization process $[34,38,45]$, laser induced pyrolysis [35] and finally the combustion synthesis $[18-30,40]$. The latter method, discussed in the present paper, is the only one capable to scale-up to large size mass production technique that could be fast, efficient and highly reproducible. Potentially, this technique could be very pure, as all additional products are very reactive ionic species which could be effectively removed by etching in acids, which could be removed by flushing in pure water. This condition is especially important for medical applications where chemical purity requirements are particularly stringent. 

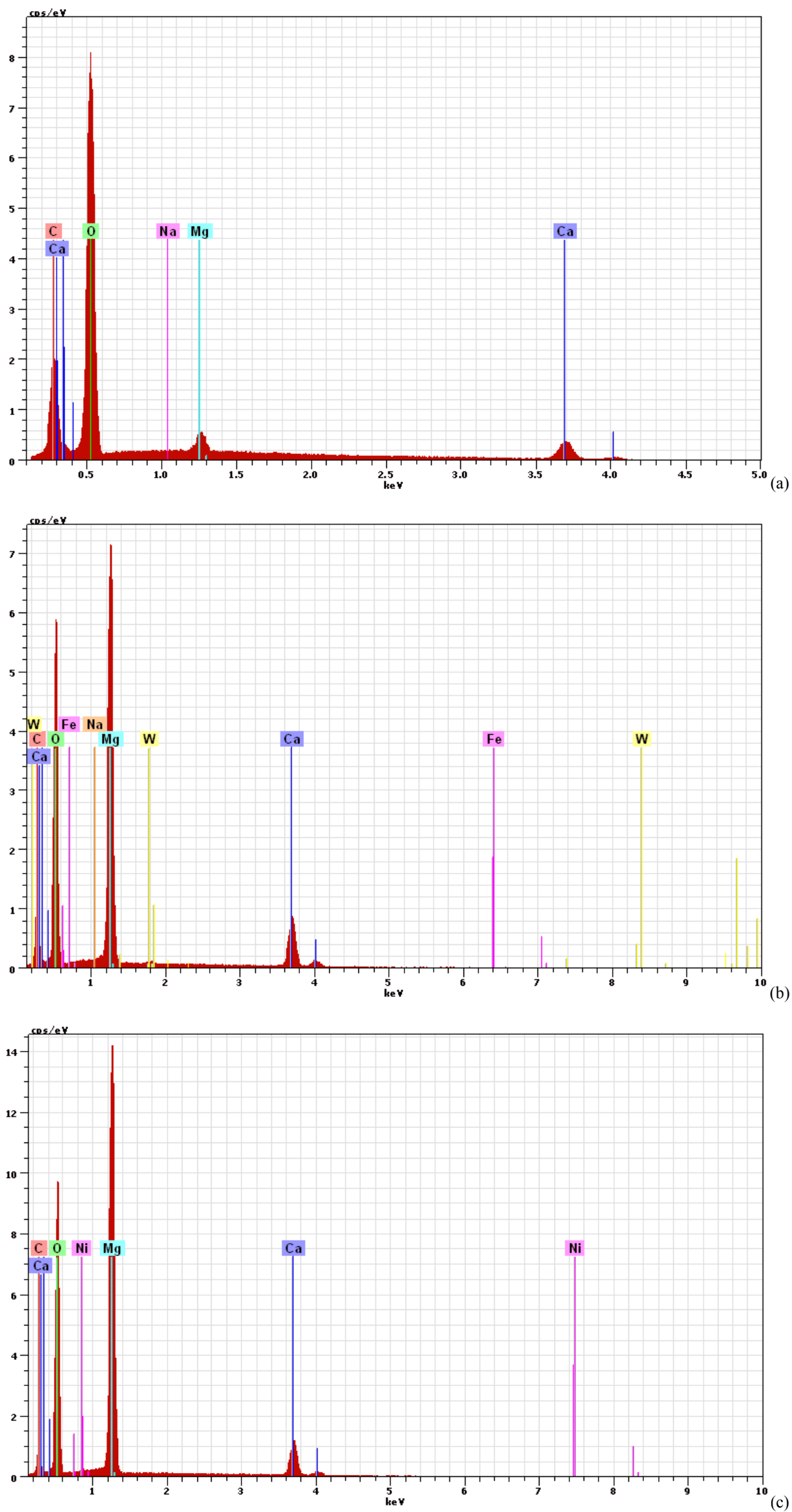

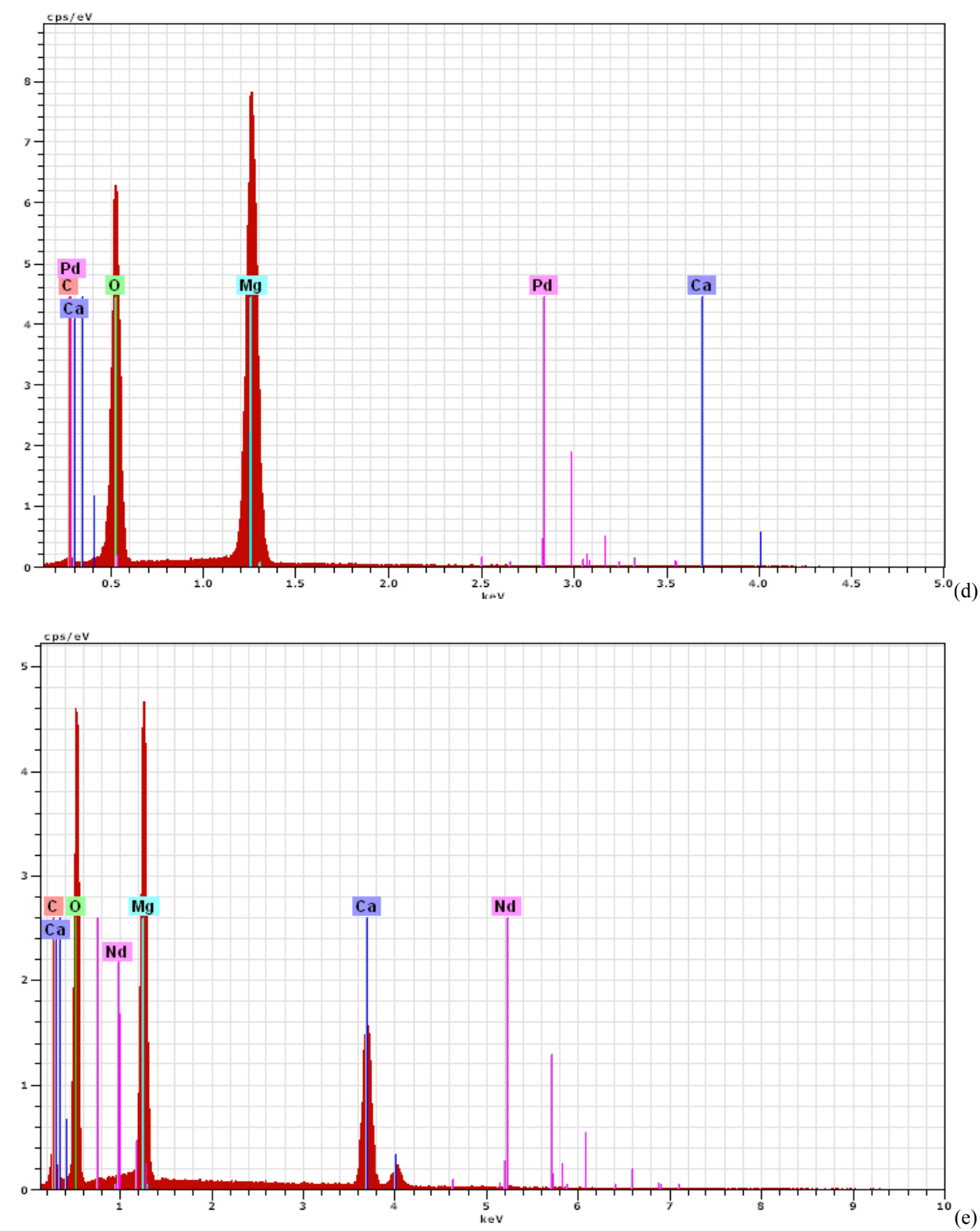

Figure 6. EDS spectra of the combustion products obtained from carbonate systems with and without metals catalysts: (a) $\mathrm{CaCO} / \mathrm{Mg}, 1 \mathrm{~atm}$ argon,(b) $\mathrm{CaCO}_{3} / \mathrm{Mg} / \mathrm{Fe}, 1 \mathrm{~atm}$ argon, (c) $\mathrm{CaCO}_{3} / \mathrm{Mg} / \mathrm{Ni}, 1 \mathrm{~atm}$ argon, (d) $\mathrm{CaCO}_{3} / \mathrm{Mg} / \mathrm{Pd}, 1 \mathrm{~atm}$ argon, (e) $\mathrm{CaCO}_{3} / \mathrm{Mg} / \mathrm{Nd}, 1 \mathrm{~atm}$ argon

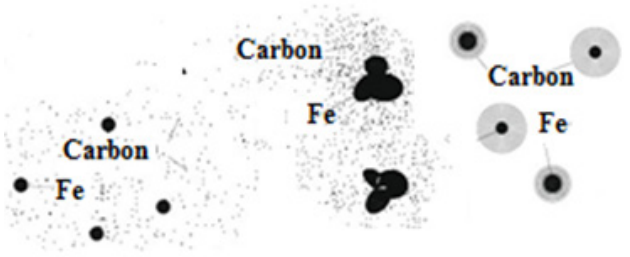

A

B

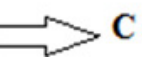

Carbon-shell or graphitic layers

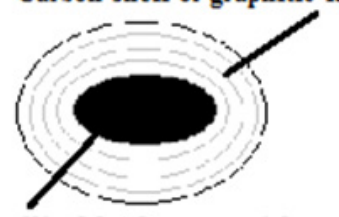

Crystallite Metal-nanoparticles

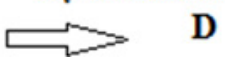

Figure 7. Model of the kinetic formation of pharmacological molecule based on nanocontainer carbon ferromagnet

Experiments are no in progress using the reaction mixture: $2 \mathrm{CF}+2 \mathrm{NaN}_{3}=2 \mathrm{NaF}+2 \mathrm{C}+3 \mathrm{~N}_{2}$ using metalcene $\mathrm{Me}(\mathrm{CO})_{5}$ $(\mathrm{Me}=\mathrm{Fe}, \mathrm{Co}, \mathrm{Ni})$ as source of metal magnetic nanoparticles encapsulated carbon in core shell structure according to the (Fig. 7)

This research will be achievement of higher content of Me-containing particles, control of particle size distribution, and also the structure of the particles. The combustion synthesis will be critically compared in the near future with combustion detonation and shock synthesis (CDS). 


\section{Acknowledgements}

We are grateful to Prof. Mark Monthieux (CEMES-Toulouse, France), Prof. Jamal Bougdira and Prof. Jaâfar Ghambaja (Institut Jean Lamour, University of Henri Point Carré, Nancy, France) for his help in HRTEM. Prof. Emeritus Andrei Huczko from the Institute of Physics, University of Warsaw, Poland) is also acknowledged for the FESEM and XRD investigations.

\section{REFERENCES}

[1] H. W. Kroto, J. R. Heath, S. C. O'Brien, R.F. Curl, and R. E. Smalley, Nature 318 (1985) 162

[2] H.W. Kroto, J. E. Fisher, and D. E. Cox, Eds., Fullerenes, Oxford: Pergamon Press (1993)

[3] S. Iijima, J. Cryst. Growth 50 (1980) 675

[4] K. S. Novoselov, A. K. Geim, S. V. Morozov, D. Jiang, Y. Zhang, S. V. Dubonos, Science 306 (2004) 669

[5] Y. Zhang, Y.W. Tan, H.L. Stormer, P. Kim, Nature 438 (2005) 201

[6] K. S. Novoselov, A. K. Geim, S. V. Morozov, D. Jiang, M. I.. Katsnelson, I. V. Grigorieva, S. V. Dubonos, A. A. Firsov, Nature 438 (2005) 197

[7] J. C. Charlier, X. Blasé, and S. Roche, Rev. Modern Phys. 79 (2007) 677

[8] J. Hass, W. A de Heer, and E. H. Conrad, J. Phys.: Condens. Matter 20 (2008) 323202

[9] Y.Q. Wu, P. D. Ye, M.A. Capano, Y. G. Prakash, and R. Reifenberger, Appl. Phys. Lett. 92 (2008) 092102

[10] A. J. van Bommel, J. E. Crombeen, A. van Thoren, Surf. Sci. 48 (1975) 463

[11] L. Li, and I. S. T. Tsong, Surf. Sci. 351 (1996) 141

[12] I. Frobeaux, J. M. Themlin, A. Charier, F. Thibaudau, and J. M. Debever, Appl. Surf. Sci. 406 (2000) 162

[13] C. Berger, Z. M. Song, T. B. Li, X. B. Li, A. Y. Ogbazghi, R. Feng, Z. T. Dai, A. N. Conrad, P. N. First, and W. A. de Heer, J. Phys. Chem. B. 108 (2004) 19912

[14] J. Hass, J. E. Millan-Otoya, P. N. First, and E.H. Conrad, Phys. Rev. B (2008) 205424

[15] J. Borysiuk, R. Bozek, W. Strupinski, A. Wysmolek, K. Grodecki, R. Stepniewski, and J. M. Baranowski, J. Appl, Phys. 108 (2009) 23503

[16] Th. Massalski, MQAter Park, OH (1990) 842

[17] W. Krätschmer, L. D. Lamb, K. Fostiropoulos, and D. R. Huffman, Nature (1990) 354

[18] Z. H. Wang, C. J. Choi, B. K. Kim, J. C. Kim, and Z. D. Zhang, Carbon 41 (2003) 1751

[19] Y. Lu, Z. Zhu, and Z. Liu, Carbon 43 (2005) 369
[20] J. H. J. Scott, and S. A. Majetich, Phys. Rev. B (1995) 12564

[21] R. S. Ruoff, D. C. Lorents, B. Chan, R. Malhotra, and S. Subramoneg, Science 259 (1993) 346

[22] J. F. Griffiths, and J. A. Barnard, Flame and Combustion, Glasgow: Academic Professional, (1995)

[23] D. R. Lide, Handbook of Chemistry and Physics, London: CRC Press LLC, (2004)

[24] H. Ellern, Military and Civilian Pyrotechnics, New York: Chemical Publishing Company, (1968)

[25] A. Varma, A. S. Rogachev, A. S. Mukasyan, S. Hwang, Adv. Chem. Eng. (1998) 79

[26] A. Huczko, M. Bystrzejewski, H. Lange, A. Fabianowska, S .Cudziło, A. Panas, M. Szala, J. Phys. Chem. B (2005) 16244

[27] E-Ch. Koch, Propell. Explos. Pyrotech. 30 (2005) 209

[28] S. CudziBů, M. Szala, A. Huczko, M. Bystrzejewski, Propell. Explos. Pyrotech. 32 (2007) 149

[29] D. Jamiola, MA Thesis, Military University of Technology, Warsaw, (2009)

[30] M. Szala, PhD Thesis, Military University of Technology, Warsaw, (2008)

[31] J. J. Delaunay, T. Hayashi, M. Tomita, S. Hirono, and S. Umemura, Appl. Phys. Lett. 71 (1997) 3427

[32] T. Hayashi, S. Hirono, M. Tomita, and S. Umemura, Nature 381 (1996) 722

[33] P. J. F. Harris, and S.C. Tsang, Chem. Phys. Lett. 293 (1998) 47

[34] B. H. Liu, J. Ding, Z. Y. Zhong, Z. L. Dong, T. White, and J.Y. Lin, Chem. Phys. Lett. 358 (2002) 96

[35] O. Bomatí-Miguel, M. P. Morales, P. Tartaj, J. Ruiz-Cabello, P. Bonville, M. Santos, X. Zhao, and S. Veintemillas-Verdaguer, Biomaterials 26 (2005) 5695

[36] N. I. Alekseev, S. G. Izotova, Yu. G. Osipov, S.V. Polovtsev, K. N. Semenov, A. K. Sirotkin, N. A. Charykov, and S. A. Kernozhitskaya, Zh. Tekh. Fiz. 76 (2006) 84

[37] D. Selbmann, B. Bendjemil, A. Leonhardt, T. Pichler, C. Täschner, and M. Ritschel, Appl. Phys. A: Mater. Sci. Process. A 90 (2008) 306

[38] B. Bendjemil, Int. J. Nanoelectr. Mater. Sci. 2 (2009) 173

[39] Z. Lou, Q. Chen, W. Wang, and Y. Zhang, Carbon 41 (2003) 3063

[40] A. Dąbrowska, A. Huczko, M. Soszyński, B. Bendjemil, F. Micciulla, I. Sacco, L. Coderoni, and S. Bellucci, Phys. Status Solidi B 248 (2011) 2704

[41] J. Borysiuk, A. Grabias, J. Szczytko, M. Bystrzejewski, A. Twardowski and H. Lange, Carbon 46 (2008) 1693

[42] M. Bystrzejewski, Z. Karoly, J. Szepvolgyi, W. Kaszuwara, A. Huczko, and H. Lange, Carbon 47 (2009) 2040

[43] B. Bendjemil, E. Borowiak-Palen, A. Graff, T. Pichler, J. Fink, and M. Knupfer, Appl. Phys. A78: Mater. Sci. Process. 
A (2004) 311

[44] E. Borowiak-Palen, T. Pichler, G. G. Fuentes, B. Bendjemil, X. Liu, A. Graff, G. Behr, R. J. Kalenczuk, Chemical communications 1 (2003) 82

[45] O. Guellati, S. Detriche, Z. Mekhalif, J. Delhalle, Int. J. Nanoelectr. Mater. Sci. 3 (2010) 123. 